\title{
An Optical Sensor Based on Polyvinyl Benzyl Malonate Cross-Linked with Divinyl Benzene Dispersed in a Hydrogel Membrane for Detection of Some Heavy Metals
}

\author{
Imad Odeh*, Ziad Shakhsher, Suha Jaber, Mahmood Khateeb, Fuad Al-Rimawi \\ Faculty of Science and Technology, Al-Quds University, East Jerusalem, Palestine \\ Email: *Odehim@Science.alquds.edu
}

Received February 12, 2012; revised March 18, 2012; accepted March 29, 2012

\begin{abstract}
In previous work we have developed a dicarboxylate functionalized polymer that demonstrated chemical sensing. It showed good response to $\mathrm{pH}$ changes as well as to varying concentrations of copper and calcium ions. Our recent investigations showed interesting results upon testing the functionalized sensing polymer on heavy metals. This sensor is composed of microspheres of polyvinyl benzyl malonate lightly-cross-linked with divinyl benzene dispersed in a hydrogel membrane. The response of the optical sensor is based on the interaction between the metal cations with the deprotonated functional group. The polymer, thus, undergoes shrinking as a result of neutralization of adjacent negative charges on the back-bone of the polymer. This causes significant changes in the optical properties of the sensing element. The optical changes were measured as absorbance vs. wavelength as the sensing membrane is exposed to solutions of varying concentrations of heavy metal ions. The sensor showed significant increase in absorbance up to a concentration of $5 \times 10^{-3} \mathrm{M}$ to the following metal ions: $\mathrm{Ni}^{2+}, \mathrm{Zn}^{2+}$, and $\mathrm{Cd}^{2+}$. Furthermore, the studied capacity of the derivatized microspheres showed close values to $\mathrm{Ni}^{2+}, \mathrm{Zn}^{2+}, \mathrm{Cd}^{2+}(1.20,1.09,1.08 \mathrm{mmol} / \mathrm{g}$ respectively). These kinds of properly functionalized polymers appear to be suitable, versatile sensing elements for the detection of low concentrations of heavy metal ions. In addition, all of the tested heavy metals showed a similar value of the equilibrium formation constant, ( $\log \mathrm{K}_{\mathrm{f} 1}$ is 2.63). In contrast, the sensor showed no significant response to varying concentrations of $\mathrm{K}^{+}$and $\mathrm{Mg}^{2+}$ metal ions.
\end{abstract}

Keywords: Shrinking Microsphere Polymer; Polyvinylbenzylmalonate; Optical Chemical Sensors; Heavy Metal Sensing; Equilibrium Formation Constant

\section{Introduction}

Chemical sensors based on swellable suitably functionalized polymer microspheres with dimensions of the order of a few micrometers suspended and entrapped in a hydrogel membrane have become of great interest in analytical studies [1-3]. The presence of heavy metals in environmental and biological samples presents an increasing concern about their toxicity. Therefore, there is a great need to develop chemical sensors for the detection of heavy metal ions [4]. Such sensors exhibit superior properties over other optical and electrical sensors due to their excellent resistance to photodegradation and electrical interference [5-7]. These sensing elements produce excellent results in a wide range of UV-visible and near IR regions.

The interaction between the deprotonated functional group on the polymer back-bone and the heavy metal ions results in neutralization of adjacent negative charges,

\footnotetext{
"Corresponding author.
}

thus causing the polymer microspheres to shrink. This leads to a lower percentage of water and hence, an increase in the refractive index of the polymer. This changes the optical properties of the polymer which can be detected by measuring either light transmission or reflection.

In 2004, a dicarboxylate functionalized polymer microsphere was prepared and its sensing to hydrogen ion $(\mathrm{pH})$, copper and calcium ions was reported [1]. In this work, a sensor composed of microspheres of polyvinyl benzyl malonate lightly-cross-linked with divinyl benzene dispersed in a hydrogel membrane, was used to detect heavy metal ions in solutions of varying concentrations. The tested heavy metal ions were $\mathrm{Ni}^{2+}, \mathrm{Zn}^{2+}$ and $\mathrm{Cd}^{2+}$.

\section{Experimental}

\subsection{Reagents}

All chemical reagents are of analytical grade and were purchased from Sigma-Aldrich Company. All solutions 
were prepared in deionized distilled water.

\subsection{Apparatus}

All the spectrophotometric measurements were carried out using a Perkin-Elmer Lambda 5 UV-visible spectrophotometer. Also, all spectrophotometric measurements were obtained at room temperature. SEM images were performed at Microscopy Lab/Faculty of Agriculture/Hebrew University.

\subsection{Capacity Determination}

The capacity of the derivatized microspheres to each of the following heavy metal ions; $\mathrm{Zn}^{2+}, \mathrm{Ni}^{2+}$, and $\mathrm{Cd}^{2+}$ was determined as follows: Direct complexometric titration with standard EDTA was done for $\mathrm{Zn}^{2+}$; Thus, one gram of the microspheres was pretreated with $0.1 \mathrm{M} \mathrm{Zn}^{2+}$ solution, then washed extensively with distilled water. The adsorbed metal ion on the polymer was eluted with $1.0 \mathrm{M}$ hydrochloric acid. Then, the eluted $\mathrm{Zn}^{2+}$ was determined by direct titration with standard EDTA solution, after the $\mathrm{pH}$ was adjusted with ammonia buffer of $\mathrm{pH} 10.0$.

The capacity to each of $\mathrm{Ni}^{2+}$ and $\mathrm{Cd}^{2+}$ ions was determined similarly as for $\mathrm{Zn}^{2+}$ except back complexometric titration was done to the eluted metal. Thus, a certain amount of standard EDTA was added to the eluted metal. Then the excess of EDTA was back titrated with standard $\mathrm{Zn}^{2+}$ after the $\mathrm{pH}$ was adjusted with ammonia buffer of $\mathrm{pH} 10$.

\subsection{Preparation of the Sensing Element}

The sensing element which is composed of microspheres of polyvinyl benzyl malonate dispersed in a hydrogel membrane was prepared as previously reported $[1,8,9]$. The reaction scheme for the preparation of the polymer is shown in Figure 1.

\subsection{Optical Measurements}

The sensing element was stuck on the inner side wall of a plastic cuvette which was secured in the cell holder of a
Perkin Elmer conventional spectrophotometer. The sensing element was positioned in the path of the light beam. The solution in the cuvette was changed by using disposable pipettes.

The change in the refractive index of the sensing element as a function of analyte concentration was measured as absorbance. The absorption spectrum was obtained at different intervals of time until steady state is reached.

Different concentrations of heavy metal ions $\left(\mathrm{Ni}^{2+}, \mathrm{Zn}^{2+}\right.$, $\mathrm{Cd}^{2+}$ ) were prepared by dissolving the metal chloride in deionized distilled water. The tested metal ion concentrations were up to $1 \times 10^{-2} \mathrm{M}$.

To regenerate the sensing element from the tested metal ion, repeated washing with $1.0 \mathrm{M}$ hydrochloric acid solution was performed in the cuvette, followed by preconditioning in a basic buffer.

\section{Results and Discussion}

The sensing element was prepared by dispersing the dicarboxylate derivatized polymer microspheres in poly vinyl alcohol crossed-linked with glutaraldehyde as prepared earlier [1,8]. The derivatized microspheres undergo swelling and shrinking as a result of protonation and deprotonation of the carboxylate group. In acidic media, the dicarboxylate is protonated and thus shrinks, while in basic media the dicarboxylate group is deprotonated and the adjacent negative charges repel causing swelling of the microspheres. This process causes a change in the refractive index of the microspheres. The change in the optical properties of the sensing membrane with the analyte concentration is monitored by the change in transmitted intensity measured as absorbance.

\subsection{Response to Metal Ions}

Previously, a good response of the optical sensor investtigated in this study to $\mathrm{Ca}^{2+}$ and $\mathrm{Cu}^{2+}$ cations was obtained [1]. In this work, similar response is observed to divalent heavy metals such as $\mathrm{Ni}^{2+}, \mathrm{Zn}^{2+}$ and $\mathrm{Cd}^{2+}$. These ions form a complex with the deprotonated dicarboxylate group causing neutralization of the negative charges on<smiles>CCOC(=O)CC(=O)OCC</smiles>

Figure 1. Synthesis of the polyvinyl benzyl malonate polymer. 
the functional group on the back-bone of the polymer, leading to shrinking of the microspheres. Scanning Electron Microscopy (SEM) of the microspheres before and after binding with the heavy metal ions $\left(\mathrm{Ni}^{2+}, \mathrm{Zn}^{2+}\right.$ and $\mathrm{Cd}^{2+}$ ) was performed to prove the shrinking of the microspheres when they bind to the heavy metal ions. Figure 2 shows the SEM images of the microspheres before and after binding with $\mathrm{Ni}^{2+}$. The size of the microspheres were calculated from the SEM images and was found to be in the range of $3.4-8.8 \mu \mathrm{m}$ and $2.9-7.7 \mu \mathrm{m}$ for the microspheres before and after binding with $\mathrm{Ni}^{2+}$, respectively. This result revealed that the microspheres shrink as a result of binding with heavy metal ions.

\subsection{Optimization of Detection Conditions of Heavy Metal Ions by the Optical Sensor}

The detection conditions of the heavy metal ions $\left(\mathrm{Ni}^{2+}\right.$, $\mathrm{Zn}^{2+}$ and $\mathrm{Cd}^{2+}$ ) were optimized by selecting the optimum $\mathrm{pH}$, and amount of microsphere. Regarding $\mathrm{pH}$, the absorbance of the sensing element was studied at different $\mathrm{pH}$ (from 4 to 10.5). Results showed that this optical sensor can be used for detection of these heavy metal ions at wide range of $\mathrm{pH}$ (from 4 - 10.5), with optimum $\mathrm{pH}$ range of $4-7.5$ as it gives high absorbance, see Figure 3. The amount of microspheres was optimized by

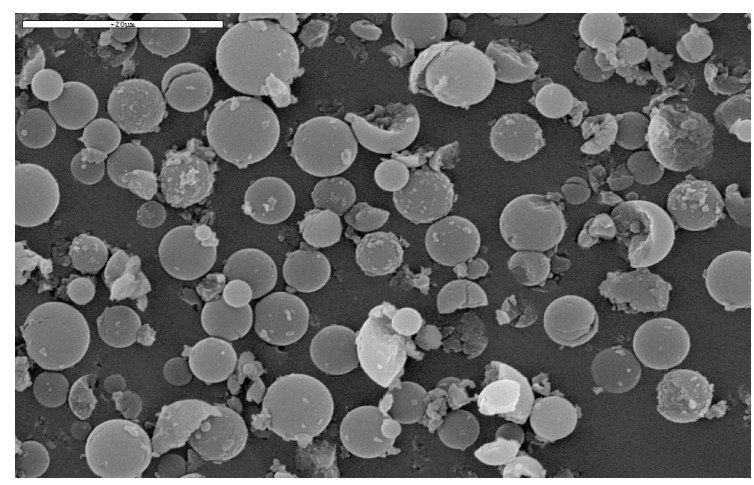

(a)

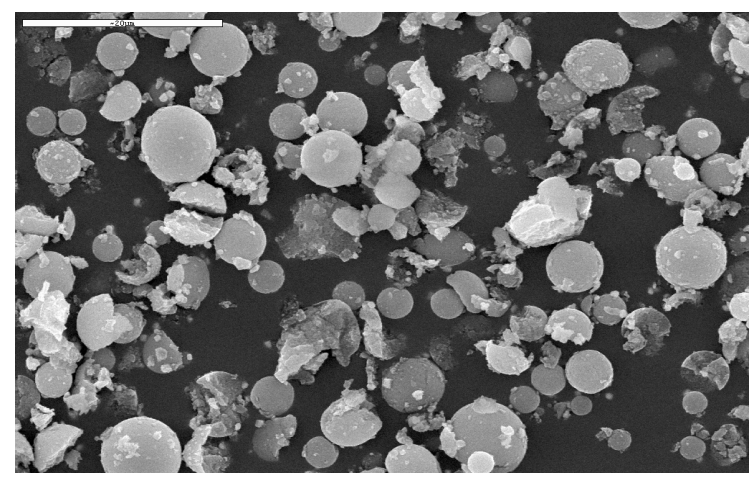

(b)

Figure 2. SEM images of the microsphere before (a) and after binding with $\mathrm{Ni}^{2+}$ (b). performing different experiments using different amounts of the microspheres and results showed that $1 \%(\mathrm{w} / \mathrm{w})$ of the microsphere in PVA gives the best detection of the heavy metal ions investigated in this study.

In the absence of divalent metal ions the deprotonated derivatized microspheres are in a swollen state and so the absorbance is low at all wavelengths (500 - $800 \mathrm{~nm}$ ) while as the metal ion concentration is increased, the microspheres start to shrink causing the absorbance to increase at all wavelength as shown in Figure 4. All the tested divalent metal ions $\left(\mathrm{Ni}^{2+}, \mathrm{Zn}^{2+}\right.$, and $\left.\mathrm{Cd}^{2+}\right)$ showed similar results. The measured absorbance vs. wave length at different concentration is typical, see Figure 5. It is obvious, that at low concentration of metal ions, the absorbance is low at all measured wavelengths. As the metal ion concentration was increased the absorbance increased with the same increment at all wavelengths. The concentrations tested ranged between zero and $1 \times 10^{-2} \mathrm{M}$ for all divalent ions under investigation $\left(\mathrm{Ni}^{2+}, \mathrm{Zn}^{2+}, \mathrm{Cd}^{2+}\right)$.

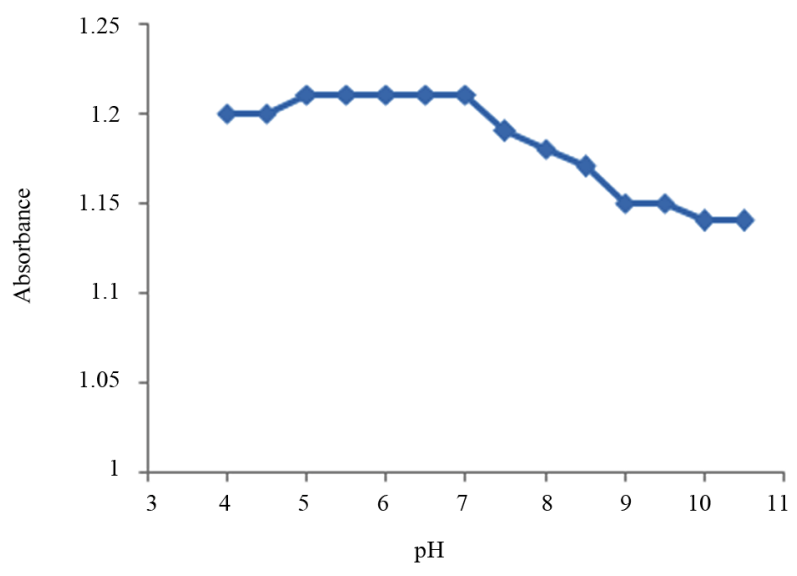

Figure 3. Absorbance of the sensing element vs. pH.

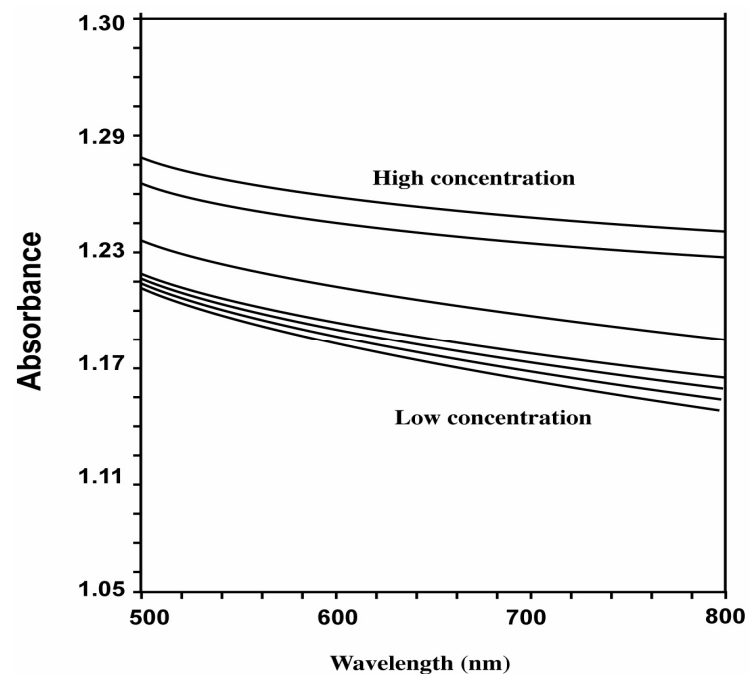

Figure 4. Variation of absorbance vs. wavelength of different $\mathrm{Cd}^{2+}$ concentrations. 
As observed in Figures 5-7, a significant increase in absorbance occurred to all of the above metal ions up to the concentration of $5 \times 10^{-3} \mathrm{M}$. As the metal ions are added, the absorbance increased until it reached a steady state. On the other hand, the capacity studies of these derivatized microspheres to the metal ions $\left(\mathrm{Ni}^{2+}, \mathrm{Zn}^{2+}\right.$, $\left.\mathrm{Cd}^{2+}\right)$ showed almost similar values $(1.20,1.09,1.08$, respectively). This is consistent with the sensor response to the concentrations of these metals.

Furthermore, the formation equilibrium constant $\left(\mathrm{K}_{\mathrm{f} 1}\right)$ to all tested metal ions was obtained from Figures 5-7. This is estimated to be equal to $\log (1 /[\mathrm{M}])$ at the point which half-way to the maximum response to metal concentration. The values of $\mathrm{K}_{\mathrm{f} 1}$ to all these metal ions are similar (2.63).

The response time of the above metal ions at concentrations of $5 \times 10^{-3} \mathrm{M}$ varied between 10 and 15 minutes, see Figure 8.

The response of the sensing element to alkali and alkaline earth metal ions such as $\mathrm{K}^{+}$and $\mathrm{Mg}^{+2}$ was investigated. The concentrations tested were up to $9 \times 10^{-1} \mathrm{M}$ and $5 \times 10^{-1} \mathrm{M}$ of $\mathrm{K}^{+}$and $\mathrm{Mg}^{2+}$ respectively. There was no

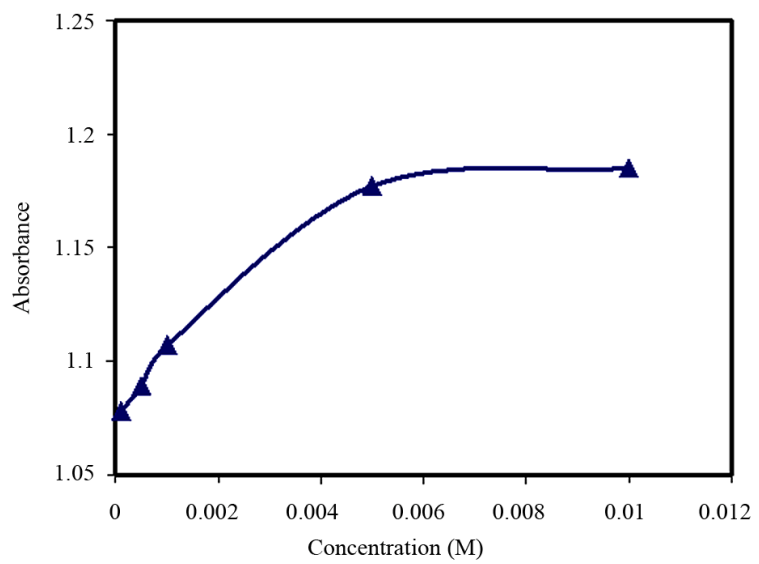

Figure 5. Turbidity absorbance vs. concentration of $\mathrm{Ni}^{2+}$.

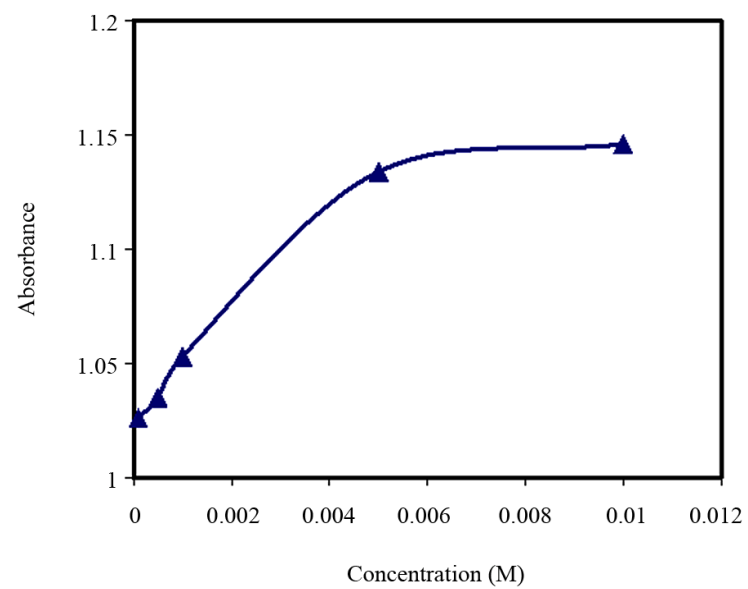

Figure 6. Turbidity absorbance vs. concentration of $\mathrm{Zn}^{2+}$. significant response to either metal ions, see Figures 9 and $\mathbf{1 0}$

\subsection{Reproducibility of the Optical Sensor}

Reproducibility of the optical sensor for detection of the heavy metal ions $\left(\mathrm{Ni}^{2+}, \mathrm{Zn}^{2+}\right.$, and $\left.\mathrm{Cd}^{2+}\right)$ was studied by repeating the detection of the heavy metal ions by the optical sensor six times at $\mathrm{pH} 7.0$ and $\mathrm{pH}$ 9.0. Reproducibility of the sensor was evaluated by calculating the relative standard deviation (RSD) of the six replicates, where results revealed that the RSD is less than $1 \%$ indicating good reproducibility of the sensor for detection of these heavy metals, see Table 1.

\section{Conclusions}

An optical sensor developed earlier was used to detect heavy metal ions particularly $\mathrm{Ni}^{2+}, \mathrm{Zn}^{2+}$ and $\mathrm{Cd}^{2+}$. Optical measurements were obtained as change in absorbance as a result of shrinking of the derivatized microspheres. This is due to the interaction between negative charges of

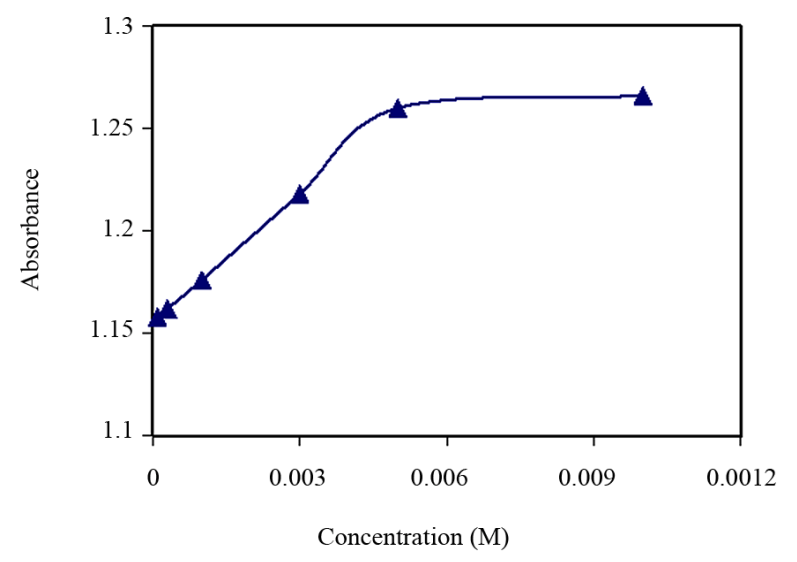

Figure 7. Turbidity absorbance vs. concentration of $\mathrm{Cd}^{2+}$.

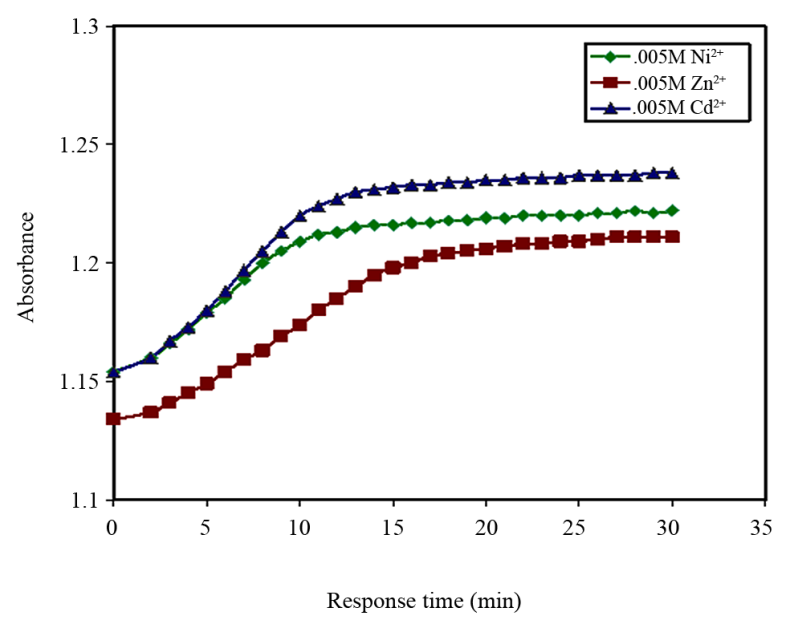

Figure 8. Turbidity absorbance vs. response time to $\mathrm{Ni}^{2+}$, $\mathrm{Zn}^{2+}$ and $\mathrm{Cd}^{2+}$. 


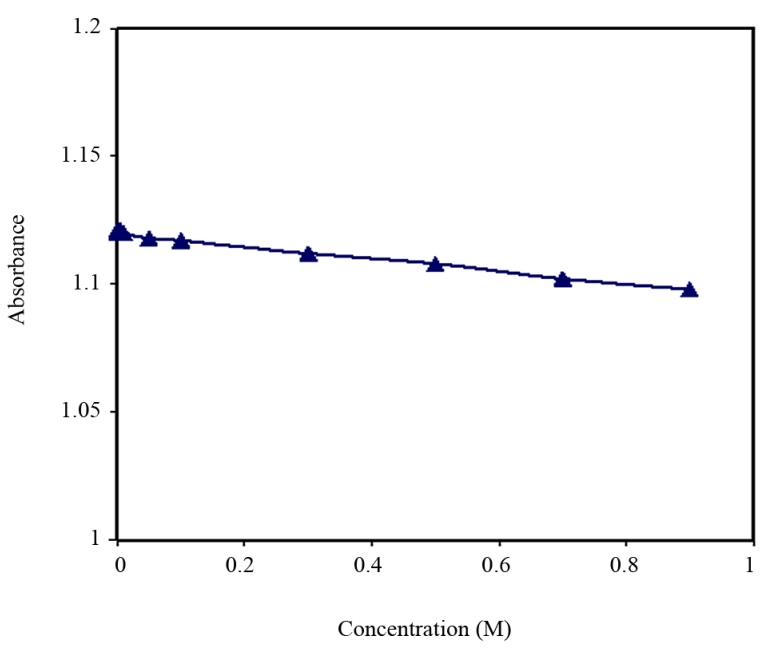

Figure 9. Turbidity absorbance vs. concentration of $\mathbf{K}^{+}$.

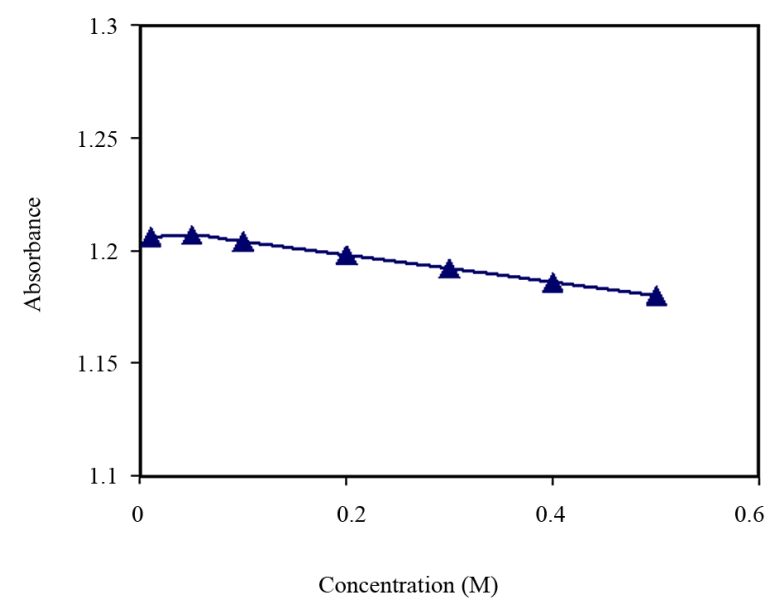

Figure 10. Turbidity absorbance vs. concentration of $\mathrm{Mg}^{2+}$.

Table 1. Absorbance of the sensor at $\mathrm{pH} 7$ and $\mathrm{pH} 9$ for six replicates.

\begin{tabular}{lccc}
\hline \multirow{2}{*}{ Replicate \# } & \multicolumn{2}{c}{ Absorbance } \\
\cline { 3 - 4 } & 1 & $\mathrm{pH} \mathrm{7.0}$ & $\mathrm{pH} 9.0$ \\
\hline 2 & 1.11 & 1.09 \\
3 & 1.10 & 1.08 \\
& 4 & 1.11 & 1.10 \\
& 5 & 1.09 & 1.09 \\
& 6 & 1.10 & 1.08 \\
Average & & 1.11 & 1.10 \\
Standard deviation & & 1.10 & 1.09 \\
Relative standard deviation (RSD) & 0.0082 & 0.0089 \\
\hline
\end{tabular}

the deprotonated functional groups on the polymer with the divalent heavy metal ions. The response measured was up to a concentration of $5 \times 10^{-3} \mathrm{M}$ to all the tested metal ions. There was no significant response to potassium and magnesium ions.
Our goal in this new line of research is to modify the sensing element with other selective functional groups to target specific chemical species that are of interest in real life applications. In addition, we are looking forward to apply this kind of optical sensing to fiber-optic technology.

\section{Acknowledgements}

The authors are indebted to the faculty of Science and Technology at Alquds University for financial support, and to George Mwangi, Necati Kaval and Huqun Liu at the University of New Hampshire for providing poly (vinylbenzyl chloride) microspheres.

\section{REFERENCES}

[1] Z. Shakasher, I. Odeh and S. Jaber, “An Optical Chemical Sensor Based on Swellable Dicarboxylate Functionalized Polymer Microspheres for $\mathrm{pH}$ Copper and Calcium Determination,” Mikrochim Acta, Vol. 144, No. 1-3, 2004, pp. 147-153. doi:10.1007/s00604-003-0077-2

[2] M. T. V. Rooney and W. R. Seitz, “An Optically Sensitive Membrane for $\mathrm{pH}$ Based on Swellable Polymer Microspheres in a Hydrogel," Analytical Communications, Vol. 36, No. 7, 1999, pp. 267-270. doi:10.1039/a902183c

[3] W. R. Seitz, M. T. V. Rooney, E. W. Miele, H. Wang, N. Kaval and L. Zhang, "Derivatized, Swellable Polymer Microspheres for Chemical Transduction,” Analytica Chemica Acta, Vol. 400, No. 1, 1999, pp. 55-64.

[4] I. Oehme and O. S. Wolfbeis, "Optical Sensors for Determination of Heavy Metal Ions,” Mikrochim Acta, Vol. 126, No. 3-4, 1997, pp. 177-192. doi:10.1007/BF01242319

[5] M. F. McCurley and W. R. Seitz, "Fiber Optic Sensor for Salt Concentration Based on Polymer Swelling," Analytica Chemica Acta, Vol. 249, No. 2, 1991, pp. 373-380. doi:10.1016/S0003-2670(00)83009-3

[6] Z. Zhang, Z. Shaksher and W. R. Seitz, “Aminated Polystyrene Membranes for a Fiber Optic pH Sensor Based on Reflectance Changes Accompanying Polymer Swelling," Mikrochim Acta, Vol. 121, No. 1-4, 1995, pp. 41-50. doi:10.1007/BF01248239

[7] Z. Shaksher, W. R. Seitz and K. D. Legg, "Single FiberOptic pH Sensor Based on Changes Accompanying Polymer Swelling,” Analytical Chemistry, Vol. 66, No. 10, 1994, pp. 1731-1735. doi:10.1021/ac00082a021

[8] Z. J. Zhang, Y. Zhang, M. Wangbai, R. Russell, Z. M. Shaksher, C. L. Grant, W. R. Seitz and D. C. Sundberg, "Poly(Vinyl Alcohol) as a Substrate for indicator Immobilization for Fiber-Optic Chemical Sensors,” Analytical Chemistry, Vol. 61, No. 3, 1989, pp. 202-205. doi:10.1021/ac00178a003

[9] T. Hirotsu, S. Katoh, K. Sugasaka, M. Sakurgi, K. Ichimura, Y. Suda, M. Fujishima, Y. Abe and T. Misonoo, "Synthesis of Dihydroxamic Acid Chelating Polymers and the Adsorptive Property for Uranium in Sea Water," Journal of Polymer Science Part A: Polymer Chemistry, Vol. 24, No. 8, 1986, pp. 1953-1966. 